\title{
Isolation of Highly Purified and Viable Retinal Endothelial Cells
}

\author{
Nicholas W. Chavkin ${ }^{a, b, c}$ Kenneth Walsh ${ }^{a, c}$ Karen K. Hirschi ${ }^{a, b, d}$ \\ ${ }^{a}$ Cardiovascular Research Center, University of Virginia School of Medicine, Charlottesville, VA, USA; ${ }^{b}$ Department \\ of Cell Biology, University of Virginia School of Medicine, Charlottesville, VA, USA; 'Department of Cardiology, \\ University of Virginia School of Medicine, Charlottesville, VA, USA; ${ }^{\mathrm{d} C a r d i o v a s c u l a r ~ R e s e a r c h ~ C e n t e r, ~ Y a l e ~ U n i v e r s i t y ~}$ \\ School of Medicine, New Haven, CT, USA
}

\author{
Keywords \\ Endothelial cells - Retinal vascular development . \\ Cell isolation - Cell purification · Cell viability
}

plications. Combining this isolation method with next-generation sequencing will enable further delineation of mechanisms underlying vascular development and maturation.

(c) 2020 S. Karger AG, Basel

\section{Introduction}

Methods for investigating endothelial cell development in vivo have revealed novel insights into mechanisms underlying blood vessel formation and maturation. One of the most widely used models for studying these processes is the neonatal mouse retina. Vascularization of the murine retina occurs postnatally, and different stages of endothelial cell growth and maturation can be studied on different postnatal (P) days (Fig. 1). At P3, the vascular plexus primarily consists of tip and stalk endothelial cells that migrate and proliferate to extend the plexus away from the optic nerve (center); at P6, the central plexus is remodeling, arteries and veins are becoming specified, and endothelial tubes are subject to systemic blood flow forces; by P9, the superficial vascular bed is established. Since blood vessels in the retina initially form in a 2-dimensional plexus, dissected tissues can be flat- karger@karger.com www.karger.com/jvr

(c) 2020 S. Karger AG, Base

Karger"
Nicholas W. Chavkin

Cardiovascular Research Center, University of Virginia School of Medicine 415 Lane Road, Suite 1010

Charlottesville VA 22908 (USA)

nwc6qu@ virginia.edu 

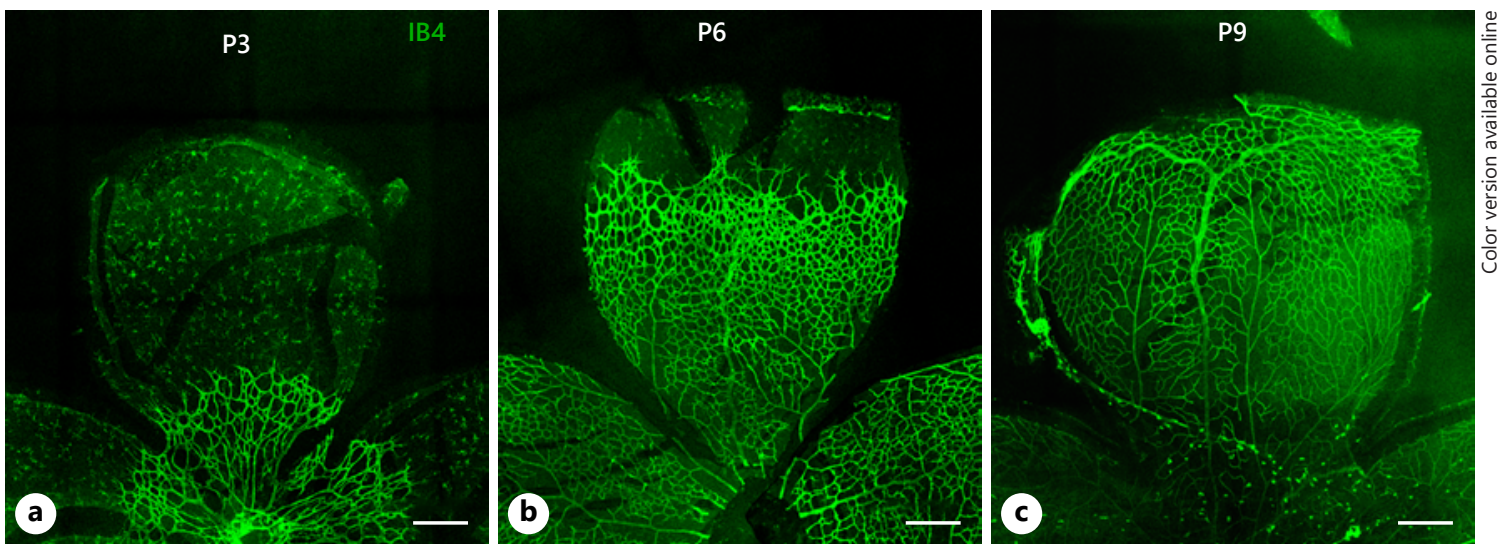

Fig. 1. Postnatal vascularization of murine retina. A vascular plexus forms first and remodels into an arterialvenous network over postnatal (P)3 (a), P6 (b), and P9 (c) time points (scale bars $=500 \mu \mathrm{m}$ ).

mounted for immunohistochemistry and imaging or digested for cell isolation $[1,2]$. Retinal vascularization can also be studied in various transgenic mouse models, and mice subjected to drug treatments and environmental stressors to investigate mechanisms and disruptions of vascular development, including arteriovenous malformations and oxygen-induced neovascularization [3-7].

Recent advances in molecular biology techniques have revolutionized how mechanisms of vascular development are investigated. Next-generation sequencing techniques allow for the generation of large RNA and DNA sequencing datasets that can be analyzed to better understand cell phenotypes and regulatory mechanisms $[8,9]$. Bulk RNA sequencing generates entire transcriptome datasets [10], and chromatin sequencing applications, including Assay for Transposase Accessible Chromatin (ATAC) sequencing [11] and chromatin immunoprecipitation (ChIP) sequencing $[12,13]$, allow for broad understanding of epigenetic landscapes and transcriptional regulation. Additionally, these techniques can be applied at single cell resolution with advances in single cell RNA [14-17], ATAC [18, 19], and ChIP [20] sequencing. Such techniques have enabled recent discoveries in vascular development and disease (reviewed in [21]); however, to take advantage of these next-generation sequencing approaches, cell populations that are pure and viable are needed for analyses $[22,23]$. Therefore, applying these techniques to the mouse retinal vascularization model requires an optimized protocol for the isolation of pure and viable retinal endothelial cells.

Two critical steps in the isolation of viable and pure single cells from tissues are tissue digestion and cell puri- fication. Enzymatic digestion of tissues can introduce experimental artifacts when not properly optimized [24]. Too little tissue digestion will limit the cell number isolated, and too much tissue digestion will induce a cellular damage response that will introduce transcriptional artifacts and decrease data quality [25]. Thus, the digestion time of the tissue is key to obtaining a high number of viable cells without inducing cell damage. Digestion methods for isolating endothelial cells have been described for several tissues [26], but digestion of retinal tissue for next-generation sequencing has not been previously described.

Additionally, next-generation sequencing requires a pure population of endothelial cells to be separated from the digested cell suspension. Current published methods use magnetic beads coated with antibodies against CD31 to pull-down endothelial cells [27]. Although this method is relatively fast and inexpensive, it does not omit undigested cell doublets or nonviable endothelial cells that will reduce the quality of next-generation sequencing data. In contrast, fluorescence-activated cell sorting (FACS) can exclude doublets (based on size) and nonviable endothelial cells (based on vital dye staining) from the purified endothelial cell population $[28,29]$. Therefore, endothelial cell purification by FACS is more compatible with next-generation sequencing.

In this study, we established a method for the isolation of endothelial cells from P6 mouse retinal tissue using an optimized collagenase type II digestion step and FACS isolation of the CD31+CD45- endothelial cell population. The overall procedure takes about $3 \mathrm{~h}$ from tissue isolation to obtaining a FACS-purified endothelial cell 


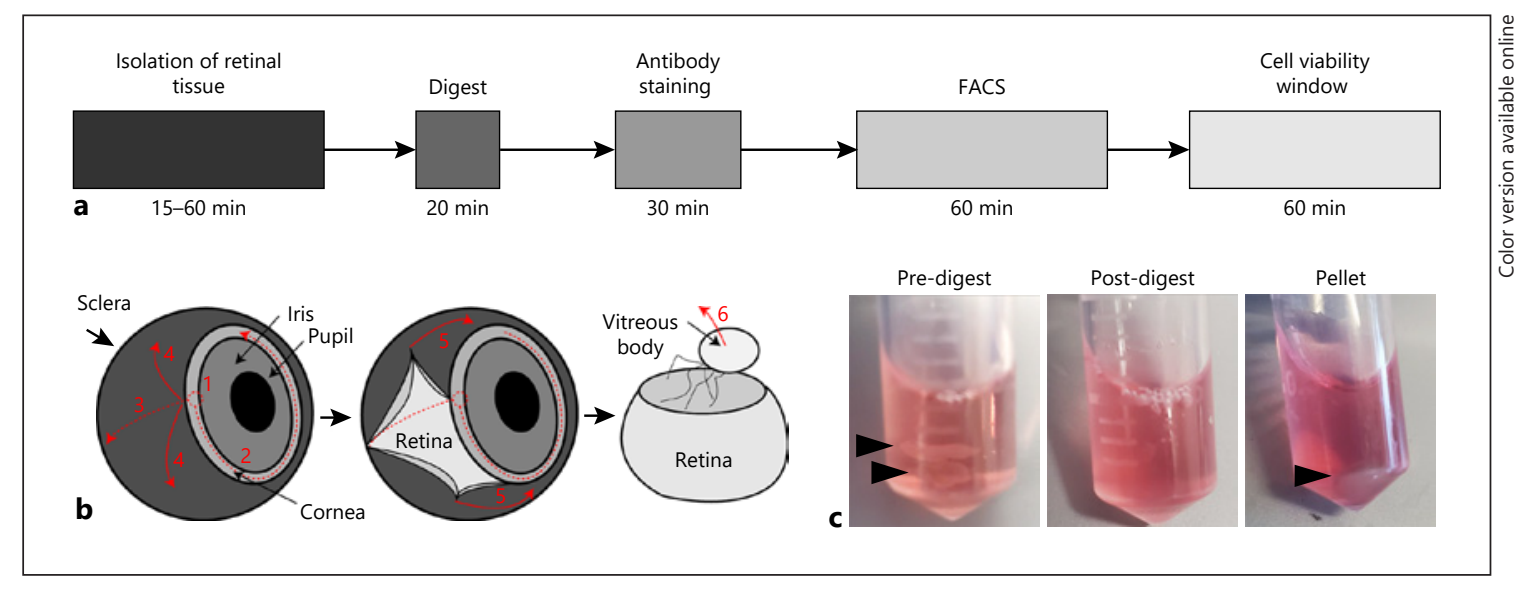

Fig. 2. Isolation of endothelial cells from mouse retinal tissue. a The progression and timeline of the method, including the following steps: isolation of retinal tissue, digestion, antibody staining, FACS, and the post-FACS cell viability window. $\mathbf{b}$ The technical removal of the retinal tissue from the mouse eye: (1) puncture the cornea, (2) tear the cornea, (3) tear the sclera, (4) peel away the

population, and these sorted cells remain viable for up to 60 min post-FACS (Fig. 2a). Using this method, pure and robust endothelial cells freshly isolated from retinal tissue can be used in next-generation sequencing approaches.

\section{Materials and Methods}

\section{Isolation of Mouse Retinal Tissue}

All animal experiments were approved by the Institutional Animal Care and Use Committees of Yale University and the University of Virginia. Neonatal mice that were 6 days postnatal (age P6) were euthanized according to the approved guidelines. Eyes were removed from euthanized mice and temporarily placed in 1 well of a 48 -well plate in $500 \mu \mathrm{L} 1 \times$ ice-cold PBS. Retinas were carefully separated from the eyes in the following manner (visual description in Fig. 2b). Under a dissection microscope (Leica M80) and using fine dissection forceps (Fine Science Cat\# 11250-00), eyes were moved to a dissection pad containing enough $1 \times$ ice-cold PBS to cover the eyes. The optic nerve was held with one of the forceps to stabilize the eye, and a hole was made by piercing through the anterior chamber at the connection between the cornea and the sclera with the other forceps. Using the forceps, the pierced hole was torn around the cornea-sclera connection in a circle $\sim 75 \%$ of the way around the cornea. The sclera was then slowly and carefully torn away from the retinal tissue. After the retinal tissue was removed from the sclera, the vitreous body was removed from the retinal tissue. Vessels of the hyaloid plexus that were not attached to the vitreous body were removed with forceps. The retinal tissue was then moved into a 2-mL Eppendorf tube containing $500 \mu \mathrm{L} 1 \times$ ice-cold PBS. The retinal tissue was sometimes fragile and torn and had to be moved in multiple pieces. Retinal tissue from 2 eyes of the same mouse were combined into 1 well. Total time of retinal tissue dissection for $4-8$ mice $(1 \mathrm{~L})$ took sclera to reveal the retina, (5) further peel away the sclera to remove the retina, and (6) remove the vitreous body and hyaloid plexus vessels. c Images of the digestion steps: retinas in the pre-digest tube (arrows), cloudy digestion solution in the post-digest tube, and the centrifuged cell pellet (arrow). FACS, fluorescence-activated cell sorting.
15-60 min from euthanasia to final retinal tissue isolation. All of the retinas in the experiment were isolated from the eyes and placed into ice-cold PBS before moving to the digestion step.

Digestion of Retinal Tissue into Single Cell Suspension

Digestion solution (DMEM with $10 \% \mathrm{FBS}$ and $1 \mathrm{mg} / \mathrm{mL}$ collagenase type II, Sigma-Aldrich Cat\# 234115), freshly made and warmed to $37^{\circ} \mathrm{C}$, was used to digest the retinal tissues and separate cells into a single cell suspension (visual description in Fig. 2c). Collagenase type II was chosen as the tissue digestion enzyme because it has been successfully implemented in the isolation and culture of endothelial cells from human tissues [30-32]. Excess PBS was removed from the 2-mL Eppendorf tubes by carefully pipetting, leaving enough PBS to cover the retinal tissue $(\sim 100 \mu \mathrm{L})$, and $500 \mu \mathrm{L}$ of digestion solution was added to each tube. Retinal tissue in the digestion solution was pipetted up and down 5 times with a P1000 pipettor and pipette tip. The digestion mixture was then incubated in a $37^{\circ} \mathrm{C}$ water bath for varying times $(10,20,30$, and $40 \mathrm{~min}$ ), pipetting the digestion mixture up and down every 5 min. For most experiments, the optimized digestion time of $20 \mathrm{~min}$ was used. After digestion, the retinal tissue was dissolved and the digestion mixture was cloudy with single cells suspended. At this stage, the digestion mixture was pelleted by centrifugation in a tabletop centrifuge at $2,000 \mathrm{rpm}(375 \mathrm{~g})$ for $5 \mathrm{~min}$ at $4^{\circ} \mathrm{C}$. The supernatant digestion solution was carefully removed by pipetting in order to not disturb the cell pellet. The pellet was then re-suspended in $500 \mu \mathrm{L}$ ice-cold $1 \times$ PBS and counted by hemocytometer. Cell counts were approximately 1 million cells per 2 retinas. Cells for control antibody/reagent staining for FACS were aliquoted into 5 new 2-mL Eppendorf tubes at 100,000 cells per tube (unstained, IgG control, propidium iodide [PI] control, CD31+ control, and CD45+ control). For control tissues that were not digested, blood was acquired from euthanized animals, and bone marrow was isolated from femurs of euthanized animals by surgical isolation of femur bone, removal of excess muscle, opening the femur at both 


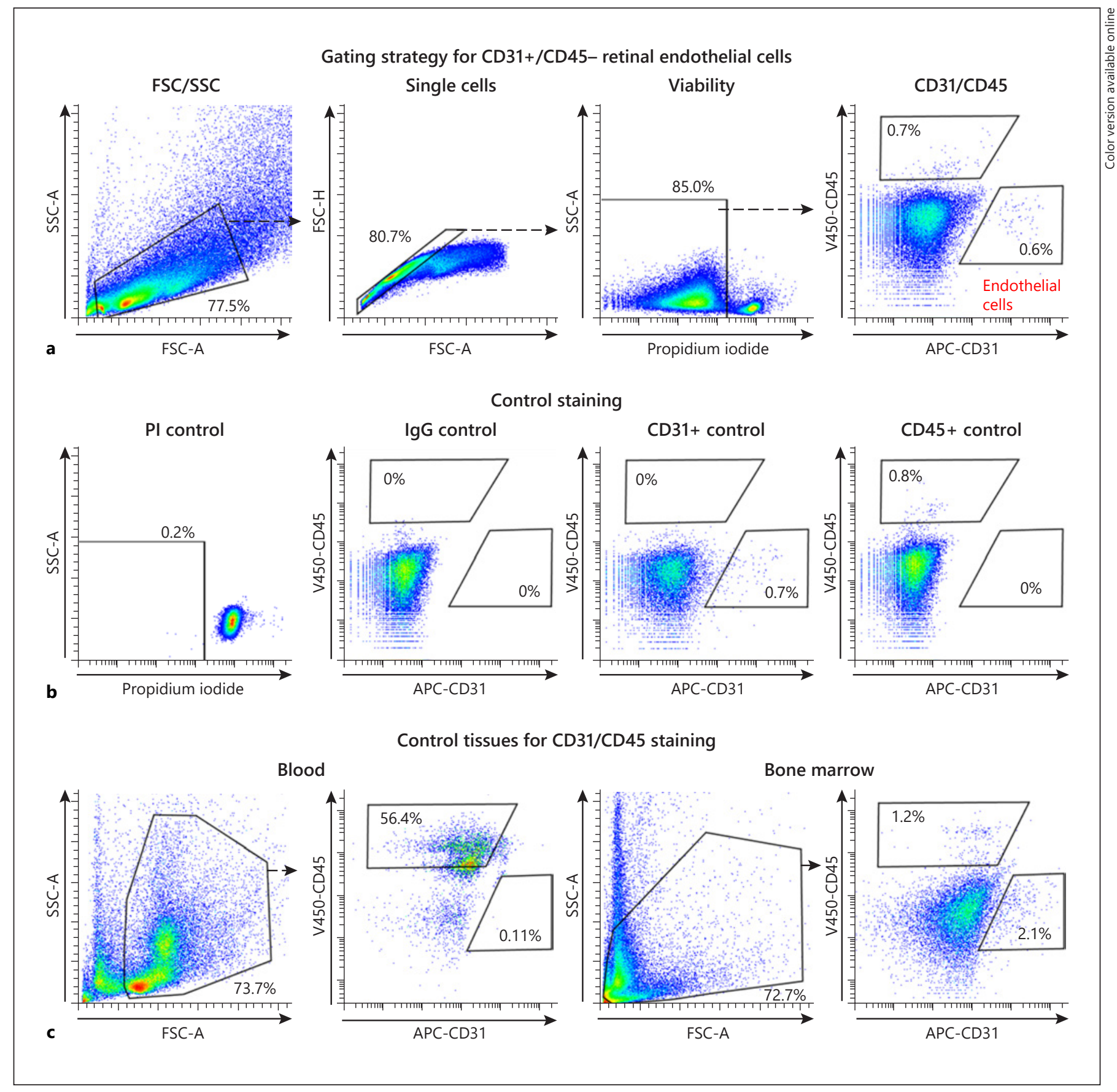

Fig. 3. FACS gating strategy for PI-/CD31+/CD45- endothelial cells. a Cells from the digested, antibody-stained cell suspension were gated by SSC-A/FSC-A, doublet discrimination selected by FSC-H/FSC-A, viable cells selected as PI-negative, and endothelial cells selected as CD31-positive and CD45-negative. b Control samples were stained using PI control sample, IgG control, CD31+ control, and CD45+ control to establish gates. c Control blood and bone marrow tissues were immunostained for CD31 and CD45 to confirm distinct cell populations. PI, propidium iodide; FACS, fluorescence-activated cell sorting. 
ends with dissection scissors, and isolation of bone marrow by injection of PBS through the femur with a $22-\mathrm{G}$ needle and collection into a 1.5-mL Eppendorf tube.

\section{Cell Suspension Prepared for FACS}

The single cell suspension was immunostained with fluorescently conjugated antibodies against CD31 (APC-CD31 BD Biosciences Cat\# 551262) and CD45 (V450-CD45 BD Biosciences Cat\# 560501), and PI (Sigma-Aldrich Cat\# P4864) was used as a viability marker. Antibody staining was performed in staining buffer (HBSS with $10 \%$ FBS, $10 \mathrm{mM}$ HEPES, $1 \mathrm{mg} / \mathrm{mL}$ D-Glucose) with a 1:100 dilution of each of the antibodies $(1 \mu \mathrm{L}$ per $100 \mu \mathrm{L}$ staining buffer, final $2 \mu \mathrm{g} / \mathrm{mL}$ antibody concentration) to make antibody staining solution. Controls were also prepared at this time: unstained control solution (no antibodies added), PI control (no antibodies added), IgG control (added APC-IgG, BD Biosciences Cat\# 553932, and V450-IgG, BD Biosciences Cat\# 560457), CD31+ control (added CD31-APC antibodies), and CD45+ control (added CD45-V450 antibodies). Additionally, early apoptotic events were quantified by Annexin V immunostaining and FACS with a control sample (added $5 \mu \mathrm{L}$ per sample Annexin V-488 staining antibody [ThermoFisher Cat\# A13201]).

Antibody staining was performed by carefully pipetting the PBS from the washed cell pellet, then re-suspending the cell pellet in $100 \mu \mathrm{L}$ of antibody staining solution per 0.5 million cells. To each of the control tubes, $10 \mu \mathrm{L}$ of the control staining solutions were added. The antibody staining solution and single cell suspensions were incubated for $30 \mathrm{~min}$ on ice, and the cells were gently mixed by tapping the tubes every $10 \mathrm{~min}$. During this time, the PI control tube was heat-shocked by incubating the cells in a $90^{\circ} \mathrm{C}$ heat block for $10 \mathrm{~min}$, then incubated on ice for the remaining time to induce cell death. After $30 \mathrm{~min}$ of total incubation time for antibody staining, the cells were pelleted by centrifugation in a tabletop centrifuge at 2,000 rpm $(375 \mathrm{~g})$ for $5 \mathrm{~min}$ at $4^{\circ} \mathrm{C}$. Cells were washed once with PBS and re-pelleted by centrifugation. Cells were re-suspended in $300 \mu \mathrm{L}$ of FACS buffer (PBS with 1\% FBS). PI was added to the sample tubes and the PI control tube (final concentration $=0.5 \mu \mathrm{g} / \mathrm{mL}$ ). Cell suspensions of digestion samples were then combined and transferred into 5-mL Falcon Test Tubes with Cell Strainer Snap Cap (Corning Cat\# 352235), filtering the solution through the $35-\mu \mathrm{m}$ filter in each cap. Control stained cells were transferred into separate FACS tubes. The FACS tubes were kept on ice and transferred to the cell sorter.

\section{Isolation of Viable Endothelial Cells via FACS}

The stained single cell suspension was sorted by FACS to isolate the viable endothelial cell population. An 85-micron nozzle on a FACSAria (BD Biosciences) was used to sort the endothelial cells to minimize collection volume and maximize density of isolated cells in the collection volume. Endothelial cells were identified through a series of gating strategies to identify the $\mathrm{PI}^{-} \mathrm{CD} 31+\mathrm{CD} 45-$ cell population (Fig. 3a). First, cells were gated based on forwardscatter and side-scatter (FSC-A and SSC-A, respectively) parameters, which identify cells based on characteristics including size, density, granularity, surface properties, and refractive index. Cell doublets were next identified as droplets containing a greater areato-height ratio of forward scattering, which denotes 2 or more cells in a single droplet by FSC-A/FSC-H gating. Viable cells were then identified as PI-negative. Finally, CD31-positive/CD45-negative endothelial cells were identified by APC/V450. Control tubes were used to determine where to set the gates on the FACS plots: viable cell gating was based on gating of the unstained and PI controls, and CD31-positive/CD45-positive cell gating was determined by the IgG control and CD31+ and CD45+ controls (Fig. 3b). Control tissues (blood and bone marrow) were used to confirm that the CD31-APC and CD45-V450 antibodies identified distinct populations (Fig. 3c). The cells were collected in 1.5-mL Eppendorf tubes containing $250 \mu \mathrm{L}$ of $1 \times$ PBS for further analysis.

\section{Viability and Gene Expression Assays}

After FACS, cell populations were kept on ice while samples were assessed for viability and gene expression. To assess cell viability, $10 \mu \mathrm{L}$ of cells were mixed with $10 \mu \mathrm{L}$ of $0.4 \%$ Trypan Blue Solution (ThermoFisher Cat\# 15250061), then the stained cell mixture was pipetted onto a hemocytometer slide and the cells were counted under the microscope. Cells that took up the Trypan Blue dye were blue in color and counted as non-viable, while clear cells were counted as viable. Percentage of viability was then calculated by viable cell count divided by total cell count. For gene expression analysis, RNA was isolated from 10,000 to 20,000 cells in each population using the RNeasy Plus Mini Kit (Qiagen Cat\# 74134), converted to cDNA with iScript cDNA Synthesis Kit (BioRad Cat\# 1708890), and quantified by SYBR-Green qRT-PCR using iTaq Universal SYBR Green Supermix (Bio-Rad Cat\# 1725120) and a Quantitative PCR Machine (CFX96 Real Time System; Bio-Rad). The following primers were used to measure gene expression: CD31 (forward: $5^{\prime}$-gagcccaatcacgtttcagttt- $3^{\prime}$, reverse: $5^{\prime}$-tccttcctgcttcttgctagct- $3^{\prime}$ ), VE-cadherin (forward: $5^{\prime}$-tcctctgcatcctcactatcaca- $3^{\prime}$, reverse: $5^{\prime}$-gtaagtgaccaactgctcgtgaat- $\left.3^{\prime}\right)$, CD 45 (forward: $5^{\prime}$-gggttgttctgtgccttgtt- $3^{\prime}$, reverse: $5^{\prime}$-ctggacggacacagttagca- $3^{\prime}$ ), and $\beta$-actin (forward: $5^{\prime}$-agagggaaatcgtgcgtgac $-3^{\prime}$, reverse: $5^{\prime}$-caatagtgatgacctggccgt- $\left.3^{\prime}\right)$.

\section{Results}

\section{Optimization of Digestion Time}

Isolation of viable endothelial cells from retinal tissue requires an optimized digestion time to release cells from the extracellular matrix of the tissue. The digestion time needs to be long enough to properly digest the tissue, but short enough to minimize the collagenase-induced cell damage, leading to nonviable cells. To determine the optimal digestion time, retinas were incubated for 10, 20, 30, or $40 \mathrm{~min}$ in the digestion solution, and the total number of viable and nonviable cells was measured per mouse. At 10-min digestion time, $~ 1,000$ endothelial cells were isolated from the retinas of each mouse, which increased to $\sim 2,000$ endothelial cells at 20-min digestion time and $\sim$ 3,000 endothelial cells at 30-min digestion time (Fig. 4a). However, the percentage of nonviable endothelial cells started to increase between 20- and 30-min digestion times, with a significant increase at 40-min digestion time (Fig. 4b). For sequencing applications, a digestion time of $20 \mathrm{~min}$ was chosen; it optimized the number of isolated 


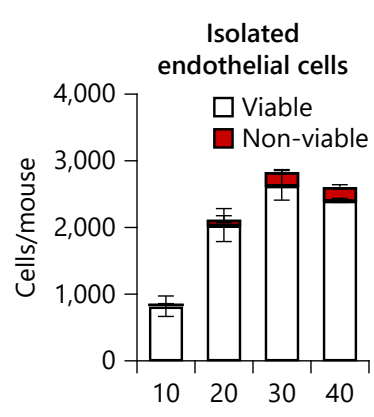

a

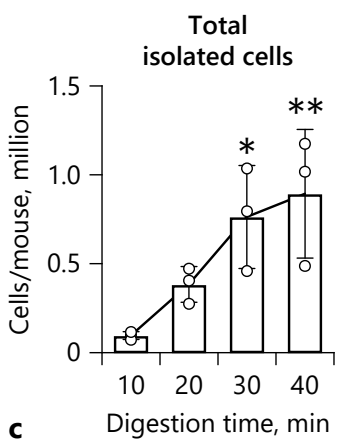

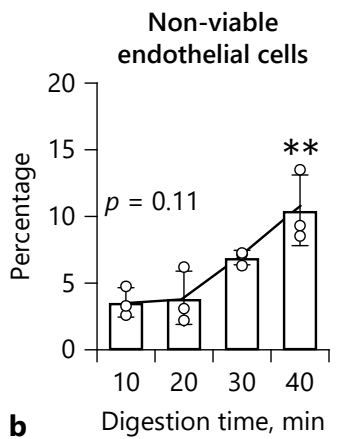

Percent endothelial cells

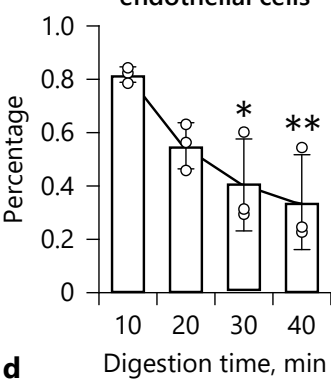

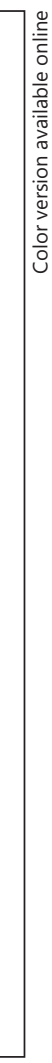

Fig. 4. Optimization of digestion time to improve endothelial cell isolation and viability. Various digestion times of 10, 20,30, and 40 min were tested. a The total number of isolated endothelial cells was quantified per mouse and separated into viable and nonviable endothelial cells, based on PI uptake. $\mathbf{b}$ The percentage of nonviable endothelial cells was calculated. $\mathbf{c}$ The total number of FACSisolated cells per mouse was measured. $\mathbf{d}$ The percentage of endothelial cells within the total isolated cells was calculated. Statistical significance of each group $(n=3)$ was measured by 1 -way ANOVA and post hoc Tukey to compare to 10 -min digestion time ( $p$ value: $*<0.05$; $\left.{ }^{* *}<0.01\right)$. PI, propidium iodide.

endothelial cells per mouse without causing increased nonviable endothelial cells. Additionally, although the total number of isolated cells increased with longer digestion times (Fig. 4c), the percentage of endothelial cells within that total digestion concomitantly decreased with longer digestion times (Fig. 4d). These results suggest that endothelial cells may be more susceptible to degradation during retinal tissue digestion in collagenase type II-containing digestion solution than some other cell types within the retinal tissue. Flow cytometry analysis of Annexin V/PI immunostaining after 20-min digestion showed $0.8 \pm 0.4 \%$ of viable endothelial cells were Annexin $\mathrm{V}$-positive, suggesting a very low percentage of cells
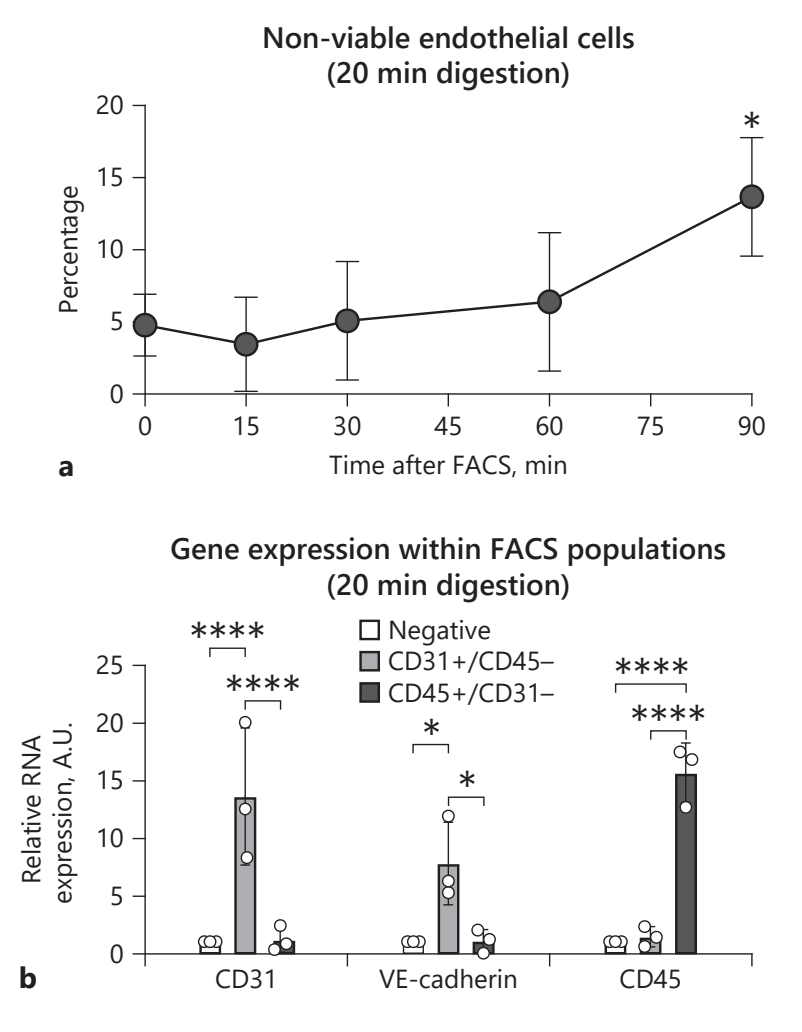

Fig. 5. Post-FACS analysis of isolated cells. Cell populations were FACS-isolated after $20 \mathrm{~min}$ of retinal tissue digestion time. a Viability of the isolated CD31+/CD45- endothelial cells was measured by Trypan Blue staining at various times between 0 and 90 min post-FACS. $\mathbf{b}$ RNA expression of CD31, VE-cadherin, and CD45 was quantified in negative, CD31+/CD45- and CD45+/ CD31 - cell populations. Statistical significance of each group $(n=$ 3 ) was measured either by 1-way ANOVA post hoc Tukey to compare with 0 -min time after FACS or by 2 -way ANOVA post hoc Tukey to compare groups $(n=3)$ between each measured gene ( $p$ value: $\left.{ }^{*}<0.05 ; * *<0.01 ; * * *<0.001{ }^{* * * * *}<0.0001\right)$.

in early apoptosis. We suggest that Annexin V not be used in the gating strategy, as this would eliminate early apoptotic events that may be important to include in the analyses of disease models and transgenic mice. Overall, the 20 -min digestion time resulted in $\sim 400,000$ total retinal cells per mouse, in which $\sim 0.6 \%$ of the total cells were CD31+/CD45- endothelial cells, yielding 2,000 endothelial cells per mouse.

\section{Assessing Viability and Purity of Endothelial Cells Post-FACS}

Next-generation sequencing applications require viable and pure cell populations; therefore, the single endothelial 
cells isolated using this method were assessed for viability and gene expression. Viability was assessed via Trypan Blue staining, which revealed that the percentage of nonviable endothelial cells remained constant for up to $60 \mathrm{~min}$ after FACS, with an increase in nonviable endothelial cells between 60 and 90 min after FACS (Fig. 5a). These results suggested that there is a short window of cell viability, up to 60 min after FACS, to process endothelial cells for nextgeneration sequencing applications. Additionally, RNA was isolated and gene expression was quantified in 3 isolated populations: $\mathrm{CD} 31-\mathrm{CD} 45-$ cells, $\mathrm{CD} 31+\mathrm{CD} 45-$ cells and CD31-CD45+ cells. The RNA from the CD31+CD45population was highly enriched for endothelial cell markers CD31 and VE-cadherin, while the CD45+CD31- population was highly enriched for CD45 RNA expression (Fig. 5b). Collectively, these data show that the isolated cell population is highly enriched for endothelial cells and is viable for up to $60 \mathrm{~min}$ after FACS isolation.

\section{Statistical Analysis}

Statistical analyses were performed using either 1-way ANOVA or 2-way ANOVA test. Multiple comparison analysis was performed using Tukey's post hoc test, comparing either one control group to all other groups or all groups within a dataset.

\section{Discussion}

In these studies, we established a protocol for the isolation of endothelial cells from retinal tissue, optimized for cell purity and viability. This method contains novel, detailed steps for tissue digestion and FACS isolation of endothelial cells that have been optimized for viability and population purity. The stringent attention to these parameters enables the isolated endothelial cells to be used for next-generation sequencing. Furthermore, the isolated endothelial cell population remained viable up to 60 min post-FACS isolation. The purity of the isolated endothelial cell population and maintenance of their viability for $60 \mathrm{~min}$ post-FACS are critical to the success of nextgeneration sequencing applications, as these techniques allow only a small amount of preparation time between FACS isolation and cell lysis.

Using this cell isolation method in the well-described retinal vascular development model, combined with nextgeneration sequencing approaches, can reveal novel insights into vascular development and maturation. The retinal vascularization model has been used to study the role of signaling pathways (VEGF, Notch, TGF- $\beta$, BMP, Hedge-

Retinal Endothelial Cell Isolation hog, and Wnt) in angiogenesis and endothelial cell fate specification during vessel formation and maturation [3338]. However, these signaling pathways are highly interconnected during blood vessel formation and remodeling [3941], and their synergistic roles are difficult to decipher. Next-generation sequencing applications can help dissect their specific, and coordinated, roles through computational analysis of signaling pathways and transcription factor networks [42-44]. Single cell analysis, combined with transgenic approaches, can further define the role of specific molecules and pathways $[45,46]$. Thus, the application of next-generation sequencing approaches to the retinal vascular development model will greatly improve our understanding of vascular development and maturation.

Modifications can be made to this method for specific applications. That is, a more specific or different cell population can be isolated by the addition or substitution of select fluorescent-conjugated antibodies. For example, studies on other tissues have shown the importance of subsets of endothelial cells expressing markers such as Gja4 [6], Esm1 [47], Apelin [48], CD34 [49], and Aqp7 [26]. Additionally, retinal tissues at different postnatal time points can be analyzed. However, the exact parameters outlined in this method should be reassessed for each time point to optimize the yield of purified endothelial cells, accounting for the overall number of endothelial cells in the tissues at various time points and/or the changing extracellular matrix composition of the tissue during development, which may affect efficiency of tissue digestion.

\section{Limitations}

This method has several limitations to consider when planning potential experiments, including low cell yield and narrow window of viability. The yield of endothelial cells using this method is relatively low, $\sim 2,000$ cells per mouse. Therefore, an average litter size of 6 pups will yield $\sim 12,000$ endothelial cells. A cell suspension this low in number may limit the downstream applications. Additionally, the limited viability of the endothelial cells after FACS sorting requires fast access to downstream processing for sequencing applications. Adjustments to methodologies may help overcome these limitations. Starting genetic material can be amplified through PCR methods to reach the necessary concentration for experimental assays. SMARTer Universal Low Input RNA Kit for Sequencing (TakaraBio Cat\# 634940), Chromium Single Cell 3' Kit v3 (10x Genomics Cat\# PN-1000092), and ATAC sequencing [11] can all be used with $\sim 12,000$ endothelial cells by incorporating a PCR amplification step after cDNA library preparation. Also, preparation time after FACS isolation in experimental 
assays may need to be shortened to maintain cell viability. Additionally, alternative digestion times or digestion enzymes could be tried that may yield higher endothelial cell numbers and percentages within digested cells; however, these changes may negatively impact cell viability compared to the method outlined here.

\section{Acknowledgements}

The authors would like to thank the Yale Flow Cytometry Core and the University of Virginia Flow Cytometry Facility for expertise and guidance on FACS experiments.

\section{Statement of Ethics}

All animal studies were approved by the Animal Use and Care Committees at Yale University and the University of Virginia.

\section{Conflict of Interest Statement}

The authors do not have any conflicts of interest to disclose.

\section{Funding Sources}

This study was supported by grants to N.W.C. (NIH T32 HL007224 and NIH T32 HL007284), K.W. (NIH R01 HL142650), and K.K.H. (NIH R01 HL146056 and NIH U2EB017103).

\section{Author Contributions}

N.W.C. wrote the manuscript, was involved in the experimental design and data analysis, and performed the experiments. K.W. and K.K.H. were involved in the experimental design, data analysis, and editing the manuscript and figures and acquired funding for the experiments.

\section{References}

1 Connolly SE, Hores TA, Smith LE, D’Amore PA. Characterization of vascular development in the mouse retina. Microvasc Res. 1988 Nov;36(3):275-90.

2 Crist AM, Young C, Meadows SM. Characterization of arteriovenous identity in the developing neonate mouse retina. Gene Expr Patterns. 2017 Jan;23-24:22-31.

3 Smith LE, Wesolowski E, McLellan A, Kostyk SK, D’Amato R, Sullivan R, et al. Oxygen-induced retinopathy in the mouse. Invest Ophthalmol Vis Sci. 1994 Jan;35(1):101-11.

4 Pitulescu ME, Schmidt I, Benedito R, Adams $\mathrm{RH}$. Inducible gene targeting in the neonatal vasculature and analysis of retinal angiogenesis in mice. Nat Protoc. 2010 Sep;5(9):151834.

5 Ruiz S, Zhao H, Chandakkar P, Chatterjee PK, Papoin J, Blanc L, et al. A mouse model of hereditary hemorrhagic telangiectasia generated by transmammary-delivered immunoblocking of BMP9 and BMP10. Sci Rep. 2016 Nov 22;5:37366.

6 Fang JS, Coon BG, Gillis N, Chen Z, Qiu J, Chittenden TW, et al. Shear-induced NotchCx37-p27 axis arrests endothelial cell cycle to enable arterial specification. Nat Commun. 2017 Dec 15;8(1):2149..

7 Ola R, Künzel SH, Zhang F, Genet G, Chakraborty R, Pibouin-Fragner L, et al. SMAD4 prevents flow induced arteriovenous malformations by inhibiting casein kinase 2 . Circulation. 2018 Nov 20;138(21):2379-94..

8 van Dijk EL, Auger H, Jaszczyszyn Y, Thermes C. Ten years of next-generation sequencing technology. Trends Genet. 2014 Sep;30(9): 418-26.

9 Slatko BE, Gardner AF, Ausubel FM. Overview of next-generation sequencing technolo- gies. Curr Protoc Mol Biol. 2018 Apr;122(1): e59.

10 Wang Z, Gerstein M, Snyder M. RNA-Seq: a revolutionary tool for transcriptomics. Nat Rev Genet. 2009 Jan;10(1):57-63.

11 Buenrostro JD, Giresi PG, Zaba LC, Chang HY, Greenleaf WJ. Transposition of native chromatin for fast and sensitive epigenomic profiling of open chromatin, DNA-binding proteins and nucleosome position. Nat Methods. 2013 Dec;10(12):1213-8.

12 Johnson DS, Mortazavi A, Myers RM, Wold B. Genome-wide mapping of in vivo proteinDNA interactions. Science. 2007 Jun 8; 316(5830):1497-502.

13 Valensisi C, Liao JL, Andrus C, Battle SL, Hawkins RD. cChIP-seq: a robust small-scale method for investigation of histone modifications. BMC Genomics. 2015;16:1083.

14 Picelli S, Faridani OR, Björklund AK, Winberg G, Sagasser S, Sandberg R. Full-length RNA-seq from single cells using Smart-seq2. Nat Protoc. 2014 Jan;9(1):171-81.

15 Macosko EZ, Basu A, Satija R, Nemesh J, Shekhar K, Goldman M, et al. Highly parallel genome-wide expression profiling of individual cells using nanoliter droplets. Cell. 2015 May 21;161(5):1202-14.

16 Hashimshony T, Senderovich N, Avital G, Klochendler A, de Leeuw Y, Anavy L, et al. CEL-Seq2: sensitive highly-multiplexed single-cell RNA-Seq. Genome Biol. 2016 Apr 28; 17:77.

17 Sasagawa Y, Danno H, Takada H, Ebisawa M, Tanaka K, Hayashi T, et al. Quartz-Seq2: a high-throughput single-cell RNA-sequencing method that effectively uses limited sequence reads. Genome Biol. 2018 Mar 9; 19(1):29.
18 Buenrostro JD, Wu B, Litzenburger UM, Ruff D, Gonzales ML, Snyder MP, et al. Single-cell chromatin accessibility reveals principles of regulatory variation. Nature. 2015 Jul 23; 523(7561):486-90.

19 Lareau CA, Duarte FM, Chew JG, Kartha VK Burkett ZD, Kohlway AS, et al. Droplet-based combinatorial indexing for massive-scale single-cell chromatin accessibility. Nat Biotechnol. 2019 Aug;37(8):916-24.

20 Grosselin K, Durand A, Marsolier J, Poitou A, Marangoni E, Nemati F, et al. High-throughput single-cell ChIP-seq identifies heterogeneity of chromatin states in breast cancer. Nat Genet. 2019 Jun;51(6):1060-6.

21 Chavkin NW, Hirschi KK. Single cell analysis in vascular biology. Front Cardiovasc Med. 2020 Mar 31;7:42.

22 Braga FAV, Miragaia RJ. Tissue handling and dissociation for single-cell RNA-seq. Methods Mol Biol. 2019;1979:9-21.

23 Potter AS, Steven Potter S. Dissociation of tissues for single-cell analysis. Methods $\mathrm{Mol}$ Biol. 2019;1926:55-62.

24 Skulska K, Wegrzyn AS, Chelmonska-Soyta A, Chodaczek G. Impact of tissue enzymatic digestion on analysis of immune cells in mouse reproductive mucosa with a focus on $\gamma \delta$ T cells. J Immunol Methods. 2019 Sep 13; 474:112665.

25 Brink SC, Sage F, Vertesy A, Spanjaard B, Peterson-Marudo J, Baron CS, et al. Single-cell sequencing reveals dissociation-induced gene expression in tissue subpopulations. Nature Methods. 2017;14(10):935-6.

26 Kalucka J, de Rooij L, Goveia J, Rohlenova K, Dumas SJ, Meta E, et al. Single-cell transcriptome atlas of murine endothelial cells. Cell. 2020 Feb 10;180(4):764-76.e20. 
$27 \mathrm{Su} \mathrm{X}$, Sorenson CM, Sheibani N. Isolation and characterization of murine retinal endothelial cells. Mol Vis. 2003 May 1;9:171-8.

28 Nicoletti I, Migliorati G, Pagliacci MC, Grignani F, Riccardi C. A rapid and simple method for measuring thymocyte apoptosis by propidium iodide staining and flow cytometry. J Immunol Methods. 1991 Jun 3;139(2): 271-9.

29 Hazen AL, Bushnell T, Haviland DL. The importance of area scaling with FACS DIVA software. Methods. 2018 Feb 1;134-135:1305.

30 Siow RC. Culture of human endothelial cells from umbilical veins. Methods Mol Biol. 2012;806:265-74.

31 Ataollahi F, Pingguan-Murphy B, Moradi A, Wan Abas WA, Chua KH, Abu Osman NA. New method for the isolation of endothelial cells from large vessels. Cytotherapy. 2014 Aug;16(8):1145-52.

32 Hewett PW. Isolation and culture of human endothelial cells from micro- and macro-vessels. In: Martin S, Hewett P, editors. Angiogenesis protocols. Methods in molecular biology; 2016. Vol. 1430; p. 61.Methods Mol Biol

33 Benedito R, Roca C, Sörensen I, Adams S, Gossler A, Fruttiger M, et al. The notch ligands Dll4 and jagged1 have opposing effects on angiogenesis. Cell. 2009 Jun 12;137(6): 1124-35.

34 Daneman R, Agalliu D, Zhou L, Kuhnert F, Kuo CJ, Barres BA. Wnt/beta-catenin signaling is required for CNS, but not non-CNS, angiogenesis. Proc Natl Acad Sci U S A. 2009 Jan 13;106(2):641-6.
35 Okabe K, Kobayashi S, Yamada T, Kurihara T, Tai-Nagara I, Miyamoto T, et al. Neurons limit angiogenesis by titrating VEGF in retina. Cell. 2014 Oct 23;159(3):584-96.

36 Crist AM, Lee AR, Patel NR, Westhoff DE, Meadows SM. Vascular deficiency of Smad4 causes arteriovenous malformations: a mouse model of hereditary hemorrhagic telangiectasia. Angiogenesis. 2018 May;21(2):363-80.

37 Kim YH, Choe SW, Chae MY, Hong S, Oh SP. SMAD4 deficiency leads to development of arteriovenous malformations in neonatal and adult mice. J Am Heart Assoc. 2018 Nov 6; 7(21):e009514

38 Ma W, Silverman SM, Zhao L, Villasmil R, Campos MM, Amaral J, et al. Absence of TGF $\beta$ signaling in retinal microglia induces retinal degeneration and exacerbates choroidal neovascularization. Elife. 2019 Jan 22;8:8.

39 Lawson ND, Vogel AM, Weinstein BM. Sonic hedgehog and vascular endothelial growth factor act upstream of the Notch pathway during arterial endothelial differentiation. Dev Cell. 2002 Jul;3(1):127-36.

40 Larrivee B, Prahst C, Gordon E, del Toro R, Mathivet T, Duarte A, et al. ALK1 signaling inhibits angiogenesis by cooperating with the notch pathway. Dev Cell. 2012 Mar 13;22(3): 489-500.

41 Wythe JD, Dang LT, Devine WP, Boudreau E, Artap ST, He D, et al. ETS factors regulate Vegf-dependent arterial specification. Dev Cell. 2013 Jul 15;26(1):45-58.
42 Davis DM, Purvis JE. Computational analysis of signaling patterns in single cells. Semin Cell Dev Biol. 2015 Jan;37:35-43.

43 Gaudet S, Miller-Jensen K. Redefining signaling pathways with an expanding single-cell toolbox. Trends Biotechnol. 2016 Jun;34(6): 458-69.

44 Aibar S, González-Blas CB, Moerman T, Huynh-Thu VA, Imrichova H, Hulselmans $\mathrm{G}$, et al. SCENIC: single-cell regulatory network inference and clustering. Nat Methods. 2017 Nov; 14(11):1083-6.

45 Trapnell C, Cacchiarelli D, Grimsby J, Pokharel P, Li S, Morse M, et al. The dynamics and regulators of cell fate decisions are revealed by pseudotemporal ordering of single cells. Nat Biotechnol. 2014 Apr;32(4):381-6.

46 Su T, Stanley G, Sinha R, D’Amato G, Das S, Rhee $\mathrm{S}$, et al. Single-cell analysis of early progenitor cells that build coronary arteries. $\mathrm{Na}$ ture. 2018 Jul;559(7714):356-6.

47 Rocha SF, Schiller M, Jing D, Li H, Butz S, Vestweber D, et al. Esm1 modulates endothelial tip cell behavior and vascular permeability by enhancing VEGF bioavailability. Circ Res. 2014 Aug 29;115(6):581-90.

48 Chen Q, Liu Y, Jeong HW, Stehling M, Dinh VV, Zhou B, et al. Apelin+ endothelial niche cells control hematopoiesis and mediate vascular regeneration after myeloablative injury. Cell Stem Cell. 2019;25(6):768-83.e6.

49 Siemerink MJ, Hughes MR, Dallinga MG, Gora T, Cait J, Vogels IM, et al. CD34 promotes pathological epi-retinal neovascularization in a mouse model of oxygen-induced retinopathy. PLoS One. 2016;11(6):e0157902. 